\title{
Seleção e número mínimo de famílias para avaliação de parâmetros de cor em uma população meio-irmã de cenoura
}

\author{
Giovani Olegário da Silva ${ }^{1 *}$, Jairo Vidal Vieira ${ }^{1}$
}

\section{RESUMO}

A utilização de um número de famílias não superior ao suficiente para bem representar determinado cruzamento, é recomendado, considerando a relação entre custo de implantação de experimentos e progresso obtido no melhoramento. Desta forma, os objetivos deste trabalho foram estimar o número mínimo de famílias de meios-irmãos de cenoura necessário para representar as características genéticas de uma população, bem como identificar as melhores famílias e plantas dentro de famílias para parâmetros de cor. O experimento foi conduzido na Embrapa Hortaliças, Gama, DF, no verão de 2004. Foi avaliada uma população híbrida com 71 famílias de meios-irmãos de cenoura, mais dois cultivares testemunhas, utilizando-se delineamento em blocos ao acaso com duas repetições de parcelas de $2 \mathrm{~m}^{2}$. Aos 90 dias após o plantio, 10 plantas por parcela foram colhidas e avaliadas para os parâmetros $\mathrm{L}^{*} \mathrm{a}^{*} \mathrm{~b}$ * do xilema e floema. Foram realizadas análises de variância e foram estimados o número mínimo de famílias para representar a população e o ganho com a seleção de $10 \%$ das melhores famílias e plantas dentro de famílias. Pode-se verificar que a seleção entre e dentro de famílias proporciona ganhos semelhantes para teor de $\beta$-caroteno para ambas as partes da raiz. Maiores ganhos com a seleção seriam obtidos para os caracteres de xilema. Para a* do xilema, ambas as testemunhas foram superadas pelas famílias selecionadas. Somente as famílias 71, 7, 61 e 20, deveriam ser selecionadas para a* do floema. Na a avaliação dos parâmetros de cor do xilema e floema, são necessárias 52 e 42 famílias, respectivamente.

Palavras-chave: Daucus carota L., $\beta$-caroteno, ganho com seleção.

\section{ABSTRACT}

\section{Selection and minimum family number for evaluation of color parameters in a half-sib carrot population}

The use of the number of families not superior to what may be considered as sufficient for a good representation of a certain crossing is recommended, but taking into account the relationship between cost of experiment implementation and the progress obtained from the breeding program. Thus, the aim of this work was to estimate the minimum number of half-sibling families of carrot necessary to represent the genetic characteristics of a population, as well as to identify the best families and the best plants inside families as to color features. The experiment was carried out at Embrapa Vegetable Crops, Gama-DF, during the summer of 2004. A hybrid population with 71 half-sibling families of carrot plus two standard cultivars were evaluated in a experiment arranged in a complete randomized block design with 2 replications, with plots measuring 2,0 $\mathrm{m}^{2}$. Ninety days after planting, 10 plants per plot were harvested and evaluated as to xylem and phloem L*a* b* parameters. The analysis of variance was performed and the minimum number of families to represent the population as well as the gains from the selection of $10 \%$ of the best families and plants inside families were estimated. It was observed that the selection among and inside families provided similar $\beta$-carotene level increases for

Recebido para publicação em dezembro de 2008 e aprovado em julho de 2009

${ }^{1}$ Engenheiros-Agrônomos, Doutores. Embrapa Hortaliças, BR 060, Km 09, C.P. 218, 70359-970, Brasília, Distrito Federal, Brasil. olegario@cnph.embrapa.br, jairo@cnph.embrapa.br. *autor correspondente. 
both root parts. Higher gains with the selection were obtained for the xylem characteristics. For xylem L* a* b*, both standard cultivars were surpassed by the selected families. Only families 71, 7, 61 and 20 should be selected for phloem L*a* b*. For the evaluation of xylem and phloem color parameters, 52 and 42 families are necessary, respectively.

Key words: Daucus carota L., $\beta$-carotene, gains with selection.

\section{INTRODUÇÃO}

O emprego do método de melhoramento de seleção recorrente, com base no desempenho de famílias de meiosirmãos, tem propiciado avanços significativos na constituição de novas populações de cenoura, adaptadas às condições edafoclimáticas brasileiras (Vieira \& Casali, 1984). Entretanto, pouca informação tem sido registrada sobre os detalhes metodológicos aplicados durante o processo de desenvolvimento desses cultivares (Vieira et al., 2006).

A avaliação de um grande número de famílias limita a utilização de maior número de plantas por cruzamento, consequentemente reduz a probabilidade de recuperar boas combinações genotípicas dentro da família (Witcombe \& Virk, 2001).

O tamanho mínimo da amostra de trabalho em ensaios de melhoramento depende da espécie, da população sob avaliação, do tipo de família, das inferências que se deseja realizar, das condições ambientais sob as quais é conduzida a população e do nível de precisão desejado (Graybill \& Kneebone, 1959; Palomino et al., 2000; Viana et al., 2002; Alves \& Seraphin, 2004). A máxima exatidão das estimativas genéticas é obtida com o mais elevado número de famílias avaliadas. No entanto, se considerar um experimento em que o número de repetições e de plantas dentro de família é adequado para reduzir a influência ambiental e representar bem determinado cruzamento, a utilização de um número de famílias não superior ao suficiente para bem representar determinado cruzamento, é recomendado, considerando a relação entre custo de implantação de experimentos e progresso obtido no melhoramento. Assim, é de interesse para os melhoristas a determinação do número mínimo de famílias a serem avaliadas para representar as características genéticas de uma população (Granate et al., 2001).

De acordo com Wu et al. (1978), para fins de melhoramento genético, o tamanho mínimo da amostra poderia ser definido como o número mínimo de elementos necessários para estimar a média e a variância de um dos caracteres da população, com precisão razoável.

Segundo Vieira et al. (2006), não existia relato formal de estudos sobre cenoura, anterior ao seu estudo, que envolvesse a determinação do número mínimo de famílias que podem representar uma população submetida à seleção para diferentes características de interesse para o melhoramento genético. Os resultados obtidos por Vieira et al. (2006) indicaram que o número de famílias varia conforme a característica e o parâmetro de interesse, e que 67 é o menor número de famílias de meios-irmãos, considerado adequado, porém neste trabalho não foram avaliados caracteres de coloração de raiz.

O teor de $\beta$-caroteno, precursor da vitamina A é uma característica importante a ser selecionada para na criação de novos cultivares de cenoura. Michalik et al. (1985) mostraram a associação entre a pigmentação mais intensa das raízes, especialmente de sua parte interna, e o maior conteúdo de caroteno. De acordo com estudos recentes realizados por Pereira \& Nascimento (2002) o uso de medidas de cor do sistema CIELAB pode substituir os métodos laboratoriais espectrofotométricos e cromatográficos que são utilizados para determinação do teor de carotenóides em cenoura.

Os objetivos deste trabalho foram estimar o número mínimo de famílias de meios-irmãos de cenoura necessários para representar as características genéticas de uma população, bem como identificar as melhores famílias e plantas dentro de famílias para parâmetros de cor.

\section{MATERIAL E MÉTODOS}

O experimento foi conduzido no campo experimental da Embrapa Hortaliças, Gama, DF. Foi avaliada uma população híbrida com 71 famílias de meios-irmãos de cenoura, mais dois cultivares testemunhas (Brasília e Alvorada), cultivados no verão de 2004, utilizando-se delineamento em blocos ao acaso com duas repetições de parcelas de $2 \mathrm{~m}^{2}$. Aos 90 dias após o plantio, foram colhidas 10 plantas por parcela, que foram avaliadas individualmente para os parâmetros $L^{*} a * b *$ do xilema e do floema das raízes, medidos por colorimetria, através de colorímetro Minolta CR 200b com sistema CIE L* a* b*. Segundo Pereira (2002), o valor de a* está relacionado ao teor de $\beta$-caroteno das raízes de cenoura. Com esses caracteres pode-se ainda calcular o ângulo Hue (cor) e a saturação (Chroma) desta cor, conforme o recomendado por Minolta (1994).

Os dados foram submetidos à análise de homogeneidade de variância (teste de Bartllet) e de normalidade (Lilliefors). Posteriormente, foi realizada análise de variância considerando efeitos entre e dentro de famílias, e análise de representatividade do número mínimo de fa- 
mílias para representar as características genéticas da população pelo método Bootstrap de Simulação de Subamostras baseado na estabilização da variância genética e da média. Para isso, iniciou-se com subamostras de cinco famílias, por ser este o menor número de raízes utilizado pelos melhoristas para representar linhagens utilizadas em combinações híbridas (Peterson \& Simon, 1986), com incremento de uma família, de uma rodada para a outra. O número de famílias foi sucessivamente aumentado até se atingir o total de 71 . Para cada tamanho de subamostra fizeram-se 15 rodadas, de forma aleatória, com reposição. Para cada subamostra, foram estimados os parâmetros genéticos, obtendo-se em seguida a média das 15 subamostras do mesmo tamanho. A estabilização dos parâmetros avaliados foi delimitada de acordo com limites superiores e inferiores do desvio padrão, tomando-se como referência a média obtida com as 71 famílias, com objetivo de tornar as medidas não subjetivas.

Para as estimativas do teor de $\beta$-caroteno pelo parâmetro a* de xilema e floema, foram selecionadas as famílias e plantas dentro de famílias com os maiores valores de $\mathrm{a}^{*}$, com pressão de seleção de $10 \%$, pelo método massal, e estimados os ganhos por seleção entre e dentro de famílias, onde GS= DS. $\mathrm{H}^{2}$, em que DS corresponde ao diferencial de seleção, ou diferença entre a média dos selecionados subtraída da média da população base e $\mathrm{H}^{2}$ à herdabilidade no sentido amplo. Nesta seleção foram consideradas as 71 famílias e incluídas também as duas testemunhas Alvorada e Brasília (genótipo 73).

As análises estatísticas foram feitas utilizando-se o aplicativo computacional Genes (Cruz, 1997).

\section{RESULTADOS E DISCUSSÃO}

De acordo com a análise de variância (Tabela 1), todos os caracteres foram significativos em diferenciar os genótipos estudados. Também para todos os caracteres os coeficientes de variação ambiental foram de magnitude baixa, indicando boa precisão experimental. A relação entre coeficiente de variação genético e ambiental entre famílias (CVge/CV) foi superior a 1 para o parâmetro b* do xilema indicando predominância de efeito de ordem genética para este caráter. Da mesma forma, valores superiores a 1 foram verificados em todos os caracteres para os efeitos dentro de famílias (CVgd/CV). Segundo Vencovsky (1987), existe uma situação muito favorável para a obtenção de ganhos na seleção quando a relação CVg/CV tende a um $(1,0)$ ou é maior que 1,0 , na medida em que, nesses casos, a variação genética supera a variação ambiental.

O valor superior da relação $\mathrm{CVg} / \mathrm{CV}$, para a* do xilema, indica que maior progresso com seleção para aumento no teor de $\beta$-caroteno seria obtido para o xilema em comparação ao ganho para o floema. A correlação genética entre essas duas características também foi estimada, com valor de 0,51 , significativo a $1 \%$ de probabilidade de erro. Este resultado indica que o aumento na quantidade de $\beta$-caroteno presente no xilema é acompanhado, medianamente, pelo aumento do mesmo no floema. Para cor de raiz, as relações $C V g / C V$ verificadas por Vieira (1988) $(0,32$ e 0,43 ) foram inferiores às estimativas para cor no presente trabalho, já o CV foi um pouco superior (12,70 a 16,40), indicando que naquele estudo a variação de ordem genética foi inferior à ambiental.

Os valores de herdabilidade baseados na média das famílias foram superiores às estimativas dentro de famílias, sendo um indicativo de que maior sucesso com a seleção seria obtido entre famílias (Tabela 1).

Timin (1991) calculou que o coeficiente de herdabilidade no sentido amplo para intensidade de cor da raiz situa-se entre 0,60 e 0,68, caráter correlacionado com o conteúdo de caroteno $(r=0,58$ a 0,68$)$. Valores de herdabilidade semelhantes aos estimados no presente trabalho. Santos \& Simon (2006) obtiveram estimativas de herdabilidade de 0,28 a 0,42, para teor de $\beta$-caroteno. Da mesma forma, para cor de raiz, Traka-Mavrona (1996) estimou herdabilidade na ordem de 0,49 a 0,86 , indicando que ganhos apenas medianos com a seleção podem ser esperados para este caráter.

Para o parâmetro a* do xilema, as melhores famílias e melhores plantas dentro de famílias foram: família 52 (planta 4), 7 (planta 1), 49 (planta 4), 50 (planta 3), 20 (planta 5), 35 (planta 5) e 15 (planta 6), sendo que a seleção destas famílias proporcionaria ganho de 7,82\% em relação à média de todas as famílias, e as médias passariam de 28,26 para 31,82. Dentre as famílias selecionadas (10\%), a família 52 foi superior numericamente às demais. A média dessa família foi de 39,99 enquanto que a segunda maior média $(31,13)$ foi obtida pela família 20. Dentre as plantas selecionadas dentro de famílias, a planta 4 pertencente à família 52, apresentou média numericamente superior às demais $(37,30)$. A segunda melhor foi a planta 5 da família 20, com média 37,20; os demais variaram de 33,80 a 36,20, valores bem superiores à média geral do caráter $(28,26)$, indicando que a seleção destas traria ganhos consideráveis. O que é confirmado pelos ganhos de 7,70\% em relação à média das famílias, ganho este muito próximo à seleção entre famílias, apesar da herdabilidade entre famílias ter sido maior. Neste caso, a diferença foi devida ao diferencial de seleção sendo que ambas as estratégias de seleção entre e dentro de famílias ocasionariam ganhos próximos a 8\% (Tabela 2).

Para o parâmetro a* do floema, as melhores famílias e correspondentes plantas dentro de famílias foram: família 61 (planta 2), 71 (planta 4), 7 (planta 1), 20 (planta 3), 72 (planta 3), 28 (planta 1) e 24 (planta 3). As médias das famílias selecionadas foram muito próximas, sendo que o 
ganho com seleção destas seria de 2,98\%, enquanto que para plantas dentro de famílias, destacaram-se a planta 4 da família 71 e a planta 1 da família 7. Para as demais, os valores foram próximos, porém superiores à média geral para esse caráter $(31,13)$. Apesar disso, o ganho com a seleção destas plantas em relação à média das famílias não seria muito alto (1,56\%). Tanto para o parâmetro a* do xilema, como para a* do floema, verificou-se que os ganhos com a seleção entre e dentro de famílias foram semelhantes; da mesma forma que as herdabilidades dos dois caracteres. Assim, para o parâmetro a* do floema, a seleção entre e dentro de famílias proporcionariam ganhos semelhantes (Tabela 2).
Para o parâmetro a* do xilema, nenhuma das testemunhas Alvorada e Brasília esteve entre as selecionadas para maior teor de $\beta$-caroteno, pois todas as famílias selecionadas foram superiores aos cultivares testemunhas, indicando progresso para estes caracteres no programa de melhoramento. No entanto, para o parâmetro a* do floema, apenas quatro famílias (71, 7, 61 e 20) foram superiores à testemunha Alvorada e, portanto, somente estas deveriam ser selecionadas.

O número mínimo de famílias necessárias para representar as características genéticas da população ou número mínimo para garantir que a seleção seja mais efetiva para os caracteres estudados, estimado através da esta-

Tabela 1. Resumo da análise de variância com informação dentro de famílias para caracteres de cor de cenoura em uma população de meios-irmãos e duas testemunhas. Brasília, 2007

\begin{tabular}{lccccccc}
\hline \multirow{2}{*}{$\begin{array}{l}\text { Fonte de } \\
\text { variação }\end{array}$} & gl & \multicolumn{7}{c}{ Quadrado Médio } \\
\cline { 3 - 8 } & & Xile-L* & Xile-a* & Xile-b* & Floe-L* & Floe-a* & Floe-b* \\
\hline Bloco & 1 & 25,63 & 112,62 & 37,66 & 385,68 & 89,11 & 577,08 \\
Famílias & 72 & $25,38^{*}$ & $97,60^{*}$ & $46,92^{*}$ & $25,70 *$ & $22,74^{*}$ & $27,95^{*}$ \\
Entre (e) & 72 & 9,00 & 37,10 & 14,92 & 9,35 & 9,78 & 15,27 \\
Dentro (d) & 1314 & 4,71 & 35,20 & 8,46 & 5,75 & 5,09 & 7,32 \\
CV & - & 2,22 & 6,81 & 2,57 & 2,15 & 3,17 & 2,41 \\
CVge/CV & - & 0,95 & 0,90 & 1,03 & 0,93 & 0,81 & 0,64 \\
CVgd/CV & - & 1,65 & 1,56 & 1,79 & 1,62 & 1,41 & 1,12 \\
H' média & - & 0,64 & 0,62 & 0,68 & 0,63 & 0,57 & 0,45 \\
H $^{2}$ Média & - & 0,52 & 0,25 & 0,56 & 0,42 & 0,38 & 0,26 \\
Ményyyyyyyy & - & 42,61 & 28,26 & 47,48 & 44,89 & 31,13 & 51,14 \\
\hline
\end{tabular}

*Significativo a $1 \%$ de probabilidade de erro pelo teste $\mathrm{F}$.

CVge e CVgd: coeficiente de variação genético entre e dentro de genótipos, respectivamente; $\mathrm{H}^{2}$ d: herdabilidade com base em plantas dentro de genótipos; Xile-L*: cor $\mathrm{L}^{*}$ do xilema; Xile-a*: cor a* do xilema; Xile-b*: cor b* do xilema; Floe-L*: cor $\mathrm{L}^{*}$ do floema; Floe-a*: cor a* do floema; Floe-b*: cor $b^{*}$ do floema.

Tabela 2. Seleção para conteúdo de $\beta$-caroteno baseado no parâmetro a* para xilema e floema em 71 famílias de uma população de meios-irmãos de cenoura mais dois cultivares testemunhas Alvorada (Família 72) e Brasília (Família 73). Brasília, 2007

\begin{tabular}{|c|c|c|c|c|c|}
\hline & & $\begin{array}{c}\text { Família } \\
\text { selecionada }\end{array}$ & $\begin{array}{c}\text { Média } \\
\text { família }\end{array}$ & $\begin{array}{c}\text { Planta } \\
\text { selecionada }\end{array}$ & $\begin{array}{c}\text { Média } \\
\text { plantas }\end{array}$ \\
\hline \multicolumn{6}{|c|}{$a^{*}$ xilema } \\
\hline DS médio & 29,90 & 52 & 39,99 & 4 & 37,30 \\
\hline $\mathrm{H}^{2}$ dentro & 25,76 & 20 & 31,13 & 5 & 37,20 \\
\hline GS (\%) dentro & 7,70 & 7 & 30,76 & 1 & 36,20 \\
\hline \multirow{4}{*}{ GS (\%) entre } & 7,82 & 35 & 30,42 & 5 & 34,20 \\
\hline & & 50 & 30,28 & 3 & 36,00 \\
\hline & & 49 & 30,13 & 4 & 33,70 \\
\hline & & 15 & 30,06 & 6 & 33,80 \\
\hline \multicolumn{6}{|c|}{ a* floema } \\
\hline DS médio & 4,09 & 71 & 33,21 & 4 & 37,70 \\
\hline $\mathrm{H}^{2}$ dentro & 38,16 & 7 & 33,10 & 1 & 37,80 \\
\hline GS (\%) dentro & 1,56 & 61 & 32,74 & 2 & 36,40 \\
\hline \multirow[t]{4}{*}{ GS (\%) entre } & 2,98 & 20 & 32,61 & 3 & 35,20 \\
\hline & & 72 & 32,58 & 3 & 37,20 \\
\hline & & 28 & 32,56 & 1 & 36,30 \\
\hline & & 24 & 32,55 & 3 & 35,70 \\
\hline
\end{tabular}

DS médio: diferencial de seleção médio; $\mathrm{H}^{2}$ dentro: herdabilidade dentro de famílias; GS: ganho de seleção. 
bilização da média e da variância genética, segundo um intervalo de confiança determinado pelo desvio padrão, está apresentado na Figura 1 para o xilema e Figura 2 para o floema.

Para o xilema, verifica-se que a estabilização da média dentro de um desvio padrão para o parâmetro L* de acor-
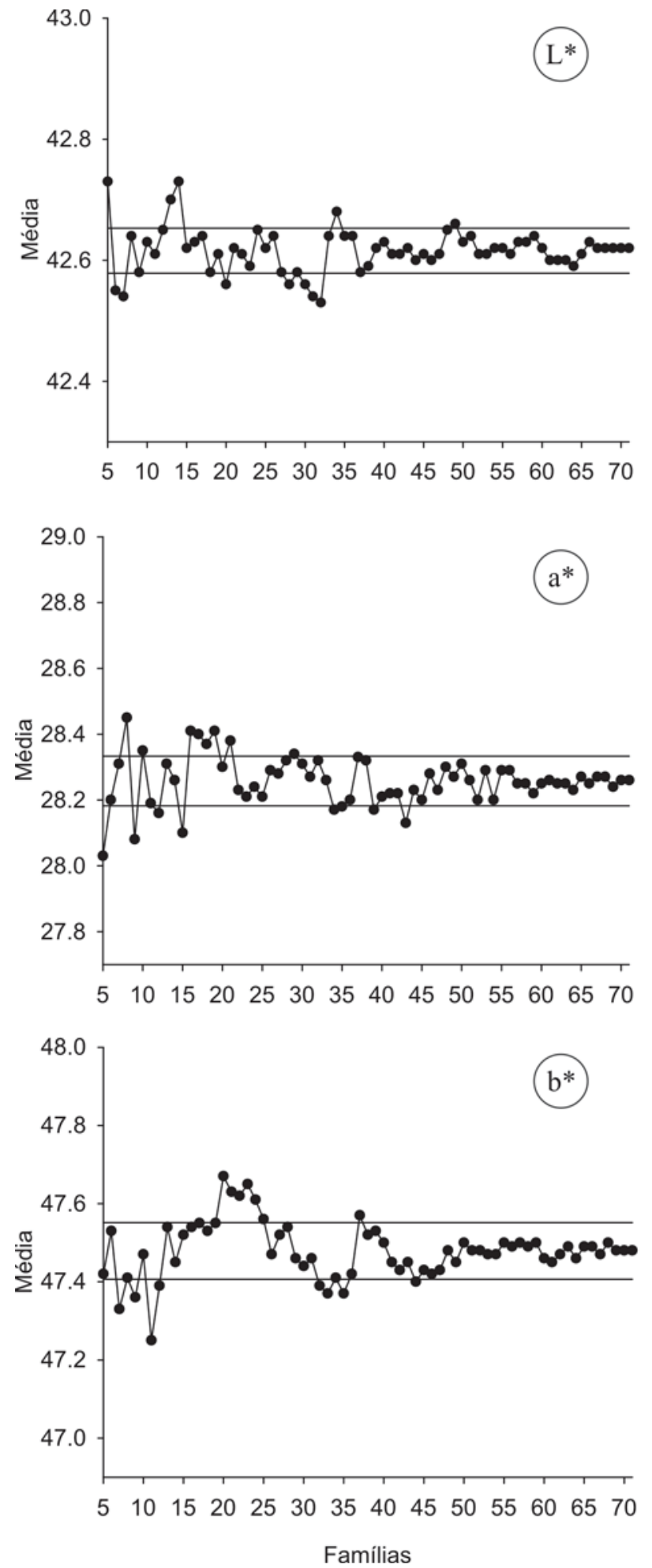

do com o primeiro ponto de uma série constante dentro dos limites de confiança, é correspondente a 50 famílias e para a variância genética a 51 famílias. Portanto, para este caráter do xilema, o número estimado mínimo de famílias deveria ser de 51. Para o parâmetro de cor a* o número mínimo de famílias dentro do desvio padrão ocorreu a
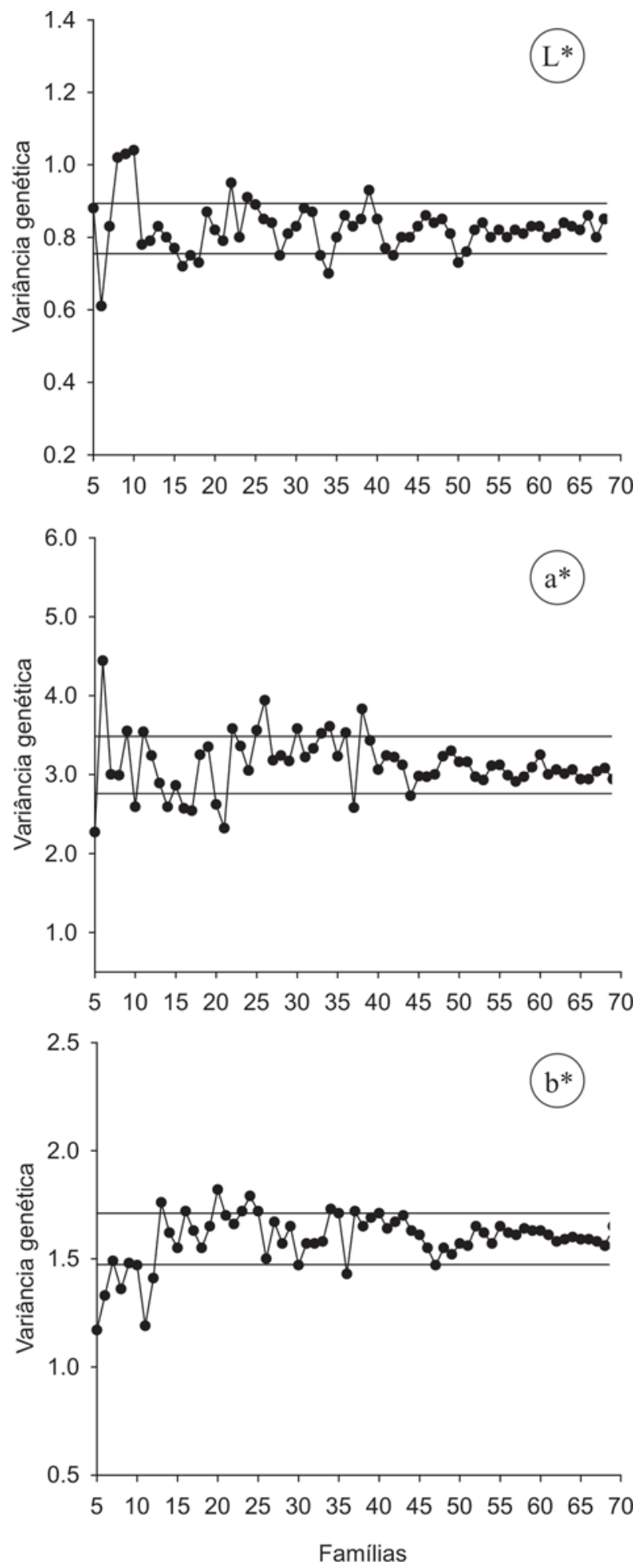

Figura 1. Número mínimo de famílias por parcela para uma população de meios-irmãos de cenoura pelo método de simulação de acordo com a estabilização da média e variância genética, para os caracteres L*a*b* do xilema. Brasília, 2007. 
partir de 44 famílias, enquanto que para a variância genética foi de 45, sendo este, portanto, o número mínimo de famílias que deve ser avaliado para este caráter. Já para a medida de cor b*, as médias se estabilizaram dentro de um limite de desvio padrão com 45 famílias, enquanto que a variância genética estabilizou com 44.
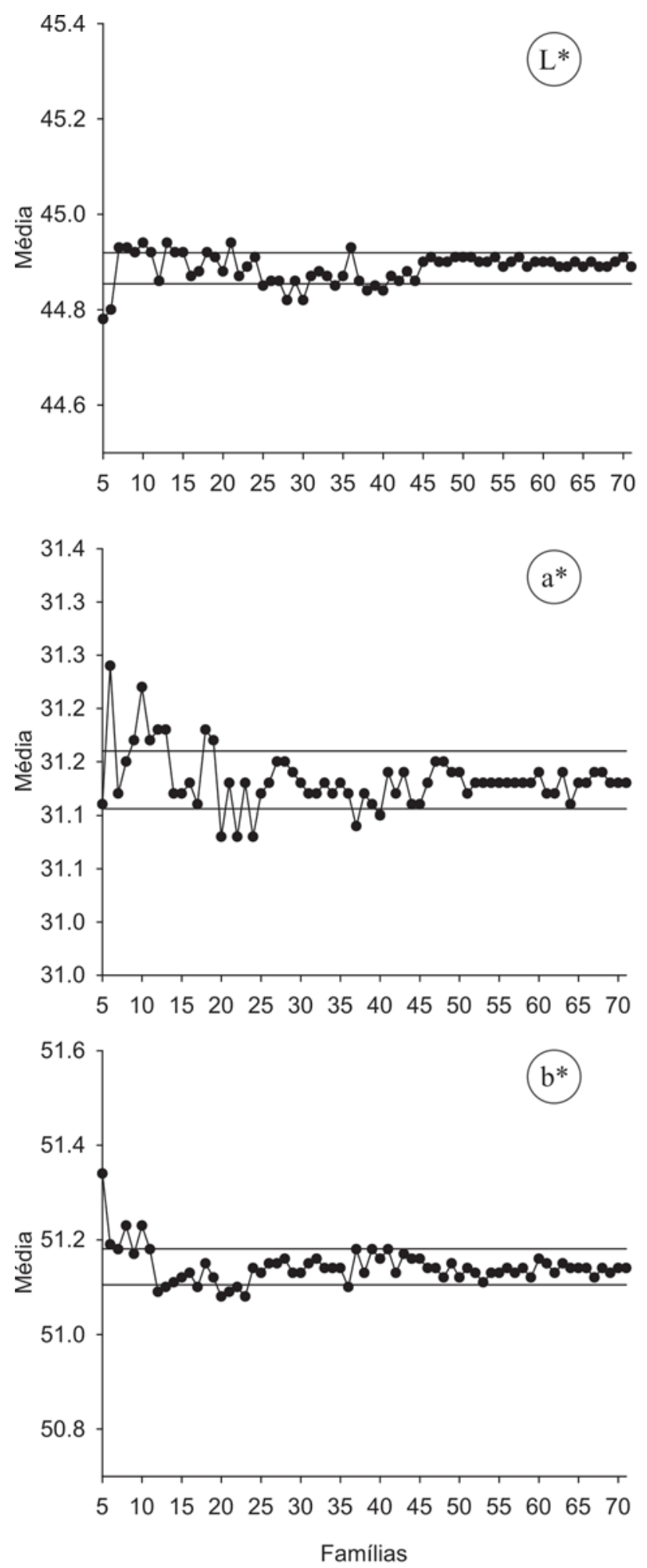

Verifica-se, portanto, que para a avaliação de cor por L* a* b* no xilema de raízes de cenoura, deve-se utilizar pelo menos 51 famílias.

Para o floema, o parâmetro L* estabilizou a partir de 41 famílias de acordo com a média e com 36 em relação à variância genética. Portanto este parâmetro pode ser avali-
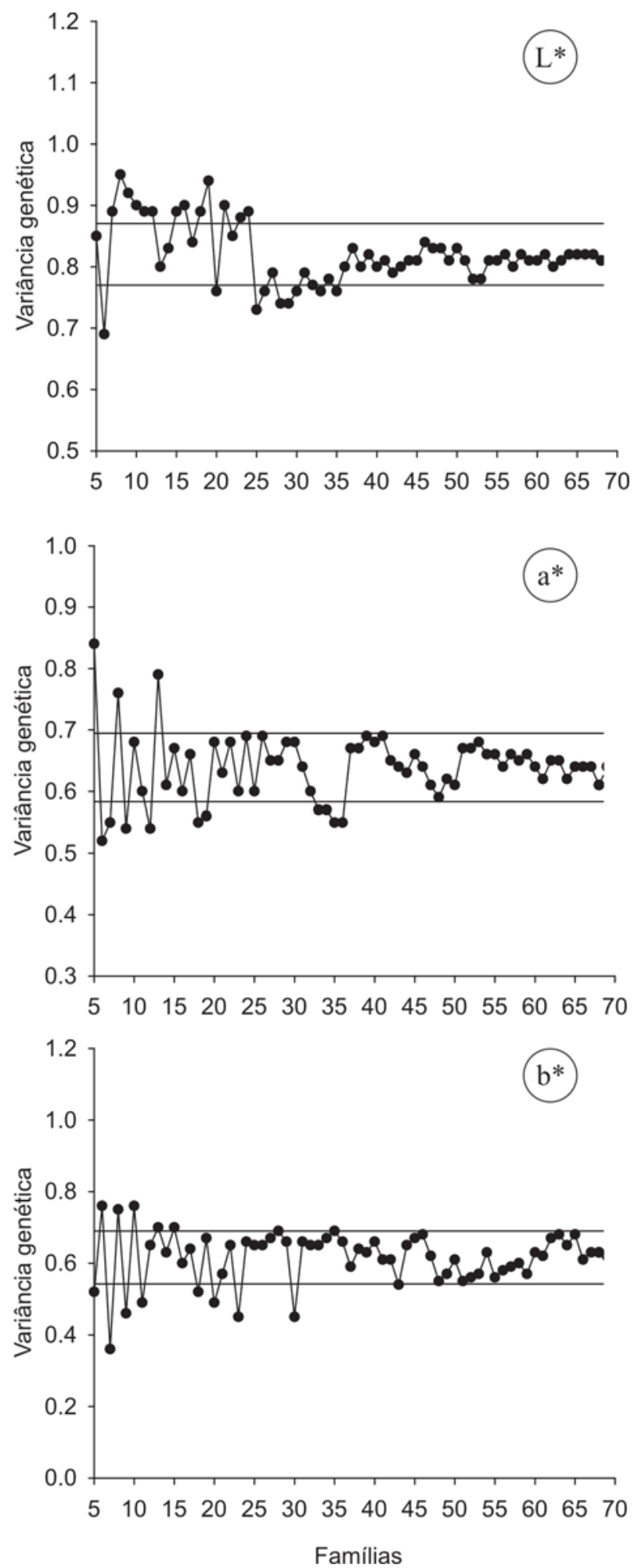

Figura 2. Número mínimo de famílias por parcela para uma população de meios-irmãos de cenoura pelo método de simulação de acordo com a estabilização da média e variância genética, para os caracteres L*a* b* do floema. Brasília, 2007. 
ado de forma mais adequada com pelo menos 41 famílias. Para o parâmetro a*, a estabilização da média ocorreu com 41 famílias e para a variância genética, a estabilização se deu com 37 famílias. Portanto, 41 é o número mínimo a ser utilizado para a caracterização desse caráter no floema. Para o parâmetro b*, a estabilização da média se deu a partir da família de número 42, e de acordo com a variância seria 36.

Verifica-se, portanto, que para estes caracteres medidos no floema, o número mínimo a ser utilizado seria de 42 famílias. Números superiores a estes não acrescentaram maiores informações e não proporcionaram redução significativa do erro de acordo com Zanon \& Storck (2000).

A estimativa de 42 famílias para o floema foi inferior à estimativa de 51 para o xilema. Isso ocorreu devido à maior influência da variação de ordem genética para o floema, conforme citado anteriormente. Também foram superiores para o floema a relação entres os coeficientes de variação genéticos e fenotípicos e a herdabilidade. Confirmando, portanto, que maior ganho com a seleção seria obtido para os caracteres desta parte da raiz.

Estes valores de número de famílias são inferiores às estimativas de Vieira et al. (2006) para os caracteres número e comprimento de folhas, massa e comprimento da raiz e primeira contagem e germinação de sementes que foi de 67. Porém estes autores consideraram como estabilização a completa linearização dos círculos e não a estabilização dentro de um intervalo de confiança de acordo com o desvio padrão. Granate et al. (2001) com milho-pipoca, também não consideraram a completa linearização dos pontos, mas visualmente identificaram pontos em que a partir destes as médias e variâncias se aproximavam da estabilização, e quando houve dúvida, optaram pelo maior valor. Entretanto, conforme os próprios autores, esta medida é subjetiva e varia com o observador. Além disso, a estabilização visual depende da escala utilizada para os eixos das ordenadas e abscissas do gráfico.

\section{CONCLUSÕES}

A seleção de famílias e a seleção de plantas dentro de famílias proporcionam ganhos semelhantes para teor de $\beta$-caroteno para ambas as partes da raiz de cenoura.

Para a avaliação dos parâmetros de cor por $\mathrm{L}^{*} \mathrm{a}^{*} \mathrm{~b}^{*}$ do xilema, são necessárias pelo menos 52 famílias e para o floema 42 famílias.

De acordo com as famílias e plantas selecionadas, maiores ganhos genéticos com a seleção são obtidos pela seleção nos caracteres de xilema.

Para a* do xilema as testemunhas são superadas pelas famílias selecionadas.

Para a* do floema somente as famílias 71, 7, 61 e 20 devem ser selecionadas.

\section{REFERÊNCIAS}

Alves SM de F \& Seraphin JC (2004) Coeficiente de heterogeneidade do solo e tamanho de parcela. Pesquisa Agropecuária Brasileira, 39:105-111.

Cruz CD (1997) Programa Genes: aplicativo computacional em genética e estatística. Viçosa, Editora Universidade Federal de Viçosa. 442p.

Granate MJ, Cruz CD \& Pacheco CAP (2001) Numero mínimo de famílias de meio-irmãos para representar uma população de milho-pipoca. Revista Ceres, 48:209-221.

Graybill FA \& Kneebone WR (1959) Determining minimum populations size for initial evaluation of breeding material. Agronomy Journal, 51:4-6.

Michalik B, Zabagalo A \& Zukowska E (1985) Investigation of the interdependence of root color and carotene content in carrot variety Selecta. Plant Breeding Abstract, 55:316.

Minolta (1994) Precise color communication: color control from feeling to instrumentation. Japão, Ramsey. 49p.

Palomino EC, Ramalho MAP \& Ferreira DF (2000) Tamanho da amostra para avaliação de famílias de meios-irmãos de milho. Pesquisa Agropecuária Brasileira, 35:1433-1439.

Pereira AS (2002) Teores de carotenóides em cenoura (Daucus carota L.) e sua relação com a coloração das raízes. Tese de Doutorado. Universidade Federal de Viçosa, Viçosa. 128p.

Pereira RS \& Nascimento WM (2002) Utilização do condicionamento osmótico de sementes de cenoura visando à germinação em condições de temperaturas altas. Horticultura Brasileira, 20 Suplemento, CD-ROM.

Peterson CE \& Simon PW (1986) Carrot breeding. In: Bassett MJ (Ed.) Breeding vegetable crops. Westport, Connecticut AVI Pub. p.321-356.

Santos CAF \& Simon PW (2006) Heritabilities and minimum gene number estimates of carrot carotenoids. Euphytica, 151:79-86.

Timin NI (1991) Genotypic variation and the heritance of characters in carrot. Plant Breeding Abstract, 61:482.

Traka-Mavrona E (1996) Effects of competition on phenotypic expression and differentiation of five quality traits of carrot (Daucus carota L.) and their implications in breeding. Scientia Horticulturae, 65:335-340.

Vencovsky R (1987) Herança quantitativa. In: Paterniani E \& Viegas GP (Eds.) Melhoramento e produção de milho no Brasil. 2 ed. Campinas, Fundação Cargill. p.137-214.

Viana AES, Sediyama T, Cecon PR, Lopes SC \& Sediyama MAN (2002) Estimativas de tamanho de parcela em experimentos com mandioca. Horticultura Brasileira, 20:58-63.

Vieira JV (1988) Herdabilidade, correlações e índice de seleção em populações de cenoura (Daucus carota L.). Tese de Doutorado. Universidade Federal de Viçosa, Viçosa. 86p.

Vieira JV \& Casali VWD (1984) Melhoramento de cenoura para verão. Informe Agropecuário, 10:17-18.

Vieira JV, Nascimento WM \& Silva JBC (2006) Número mínimo de famílias de meios-irmãos para avaliação de uma população de cenoura. Pesquisa Agropecuária Brasileira, 41:365-367.

Zanon MLB \& Storck L (2000) Tamanho ótimo de parcelas experimentais para Eucalyptus saligna Smith em dois estádios de desenvolvimento. Cerne, 6:104-111.

Witcombe JR \& Virk DS (2001) Number of crosses and population size for participatory and classical plant breeding. Euphytica, 122:451-462.

Wu KK, Heinz DJ, Meyer HK \& Ladd SL (1978) Minimum sample size for estimating progeny mean and variance. Crop Science, 18:57-62. 